\title{
Influência da dopagem com Fe nas propriedades estruturais e eletrônicas do $\mathrm{TiO}_{2}$ anatase e rutilo.
}

Ericson H. N. S. Thaines ${ }^{1}(\mathrm{PG})$, Juliana K. C. Salgado ${ }^{1}(\mathrm{PG})$, Ailton J. Terezo $(\mathrm{PQ})$ Paulo R. G. Gonçalves ${ }^{2}(\mathrm{PG})$, Gabriel L.C. Souza ${ }^{1}(\mathrm{PQ})$, Hélio A. Duarte ${ }^{2}(\mathrm{PQ})$, Renato G. Freitas ${ }^{1}(\mathrm{PQ})$.

Email:rgfreitas@ufmt.br

${ }^{1}$ Departamento de Química/LCM, UFMT, 78060-900 Cuiabá-MT Brasil

${ }^{2}$ Departamento de Quimica, UFMG, 31270-901 Belo Horizonte-MG, Brasil.

Palavras-chave: $\mathrm{TiO}_{2}$, Semicondutor, DFT, Rietveld.

O Dióxido de titânio $\left(\mathrm{TiO}_{2}\right)$ é um semicondutor que tem apresentado um crescente interesse devido à sua versatilidade em aplicações tecnológicas ${ }^{1}$. As fases cristalinas anatase e rutilo do $\mathrm{TiO}_{2}$ destacam-se nas aplicações, apresentando um valor de band-gap de 3.2 e 3,0 eV, respectivamente. A inserção de átomos dopantes nas estruturas cristalinas podem modificar as propriedades dos semicondutores como o decréscimo no band-gap ou na taxa de recombinação elétron-buraco. Assim, o átomo de Fe tem sido uma alternativa para a dopagem na estrutura do $\mathrm{TiO}_{2}{ }^{2}$. O presente trabalho apresenta um estudo teórico/experimental do $\mathrm{TiO}_{2}$ dopado com ferro.

Nanopartículas de $\mathrm{TiO}_{2}$ puras e dopadas com ferro foram sintetizadas através do método de Pechini. A difração de raio-X (DRX) foi utilizada para a caracterização estrutural e pelo refinamento de Rietveld foi obtido os parâmetros de rede das estruturas cristalinas. Os cálculos teóricos foram realizados através da Teoria do Funcional da Densidade (DFT) ${ }^{3,4}$ implementado no pacote computacional QuantumESPRESSO $^{5}$ e um funcional de troca-correlação descrito por Perdew e Wang (PW91) ${ }^{6}$.

A Fig. 1-a mostra o difratograma experimental para o $\mathrm{TiO}_{2}$ dopado com $0,5 \%$ de $\mathrm{Fe}$, sugerindo que tal átomo ocupou um sitio na estrutura cristalina do $\mathrm{TiO}_{2}$, uma vez que não foi observado a fase $\mathrm{Fe}_{2} \mathrm{O}_{3}$.

(a)

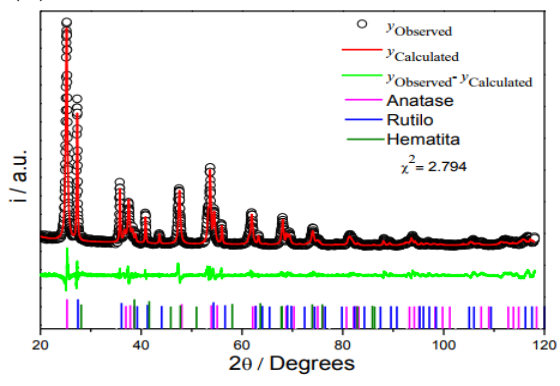

(b)

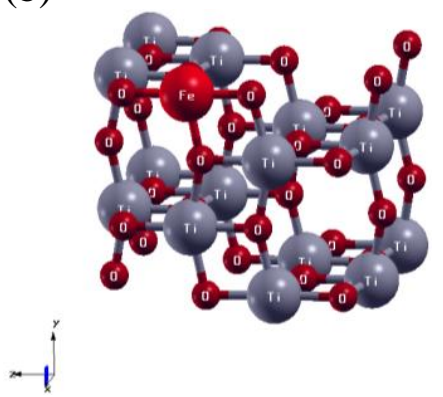

(b)

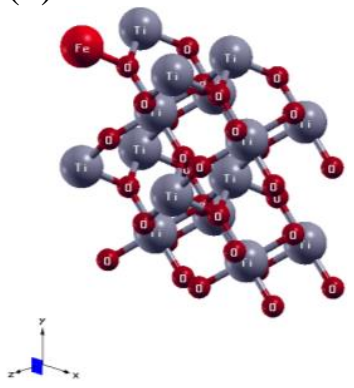

Figura 1 - (a) Refinamento de Rietveld para $\mathrm{TiO}_{2(0,5 \% \mathrm{Fe})}$. Cálculos relax da supercélula dopada com Fe para (b) Anatase (100) e (c) Rutilo (100).

Para o estudo da dopagem, foi construída uma supercélula para anatase Fig. 1-b e rutilo Fig.1-c com 48 átomos com o objetivo de simular a dopagem experimental. Observa-se que a introdução de um átomo de $\mathrm{Fe}$ na estrutura cristalina do $\mathrm{TiO}_{2}$ diminui o valor de band-gap e provocou uma modificação na distribuição da densidade de estados parciais (PDOS). Modificações significativas nos valores de ELF e mapa de carga também foram observadas. Portanto, a dopagem de $\mathrm{Fe}$ em $\mathrm{TiO}_{2}$ pode ser obtida experimentalmente e cálculos teórico colaboram para elucidação dos sítios de dopagem. Os autores agradecem ao CNPq (427167/2016-9), FAPEMAT (214599/2015) e INCTACQUA.

[1] Diebold, U.; Surf. Sci. Rep. 2003, 48, 53

[2] Wang, X.H. et al.; J. Phys.Chem. B. 2006, 110, 21.

[3] P. Hohenberg and W. Kohn, Phys. Rev., 1964, 136, B864.

[4] W.Kohn and L.J.Sham, Phys. Rev., 1965,140, A1133.

[5] G. Paolo et al, J. Phys.:Condens. Matter, 2009, 21.

[6] J. P. Perdew and Y. Wang, Phys. Rev. B, 1986, 33. 